José Manuel Castanheira, com a maqueta do espectáculo

\section{José Manuel Castanheira}

Nasceu em Castelo Branco, em 1952. Licenciou-se em Arquitectura pela Escola Superior de Belas Artes de Lisboa. Professor da Faculdade de Arquitectura de Lisboa, desde 1982, foi director técnico do Teatro Nacional D. Maria II. Apresentou o seu primeiro trabalho cenográfico em 1973: Os pequenos burgueses de Gorki, uma encenação de Fernanda Lapa para o Grupo de Iniciação Teatral da Trafaria, na sala do casino local. A sua vasta obra cenoplástica tem sido distinguida com vários prémios e foi objecto de duas importantes exposições retrospectivas: "O EspaçoMemória", no Centro de Arte Moderna da Fundação Calouste Gulbenkian, em 1989, e "Cenografias 1973-1993", no Centro Georges Pompidou (1993), organizada por Carlos Alberto Machado.

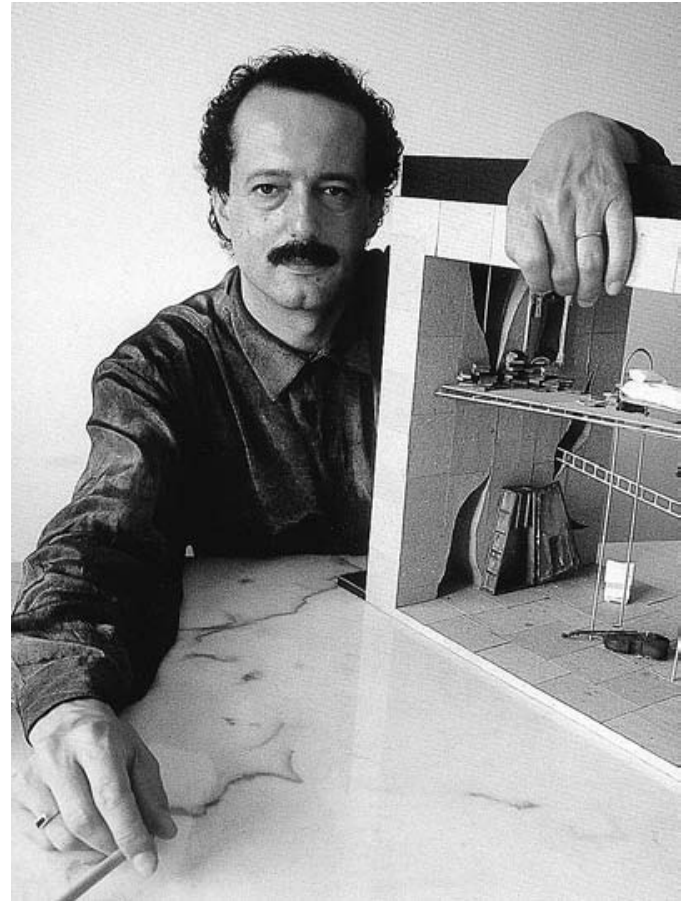

\title{
Persistências e adaptações
}

\author{
Luiz Francisco Rebello
}

Eu não sei como explicar porque faço um determinado cenário. Quais os mecanismos? As referências? Múltiplas e complexas. A construção de um espaço tem sempre a ver com a decomposição de outros. Diz respeito a uma vontade própria de redistribuir ideias, de inventar uma nova perspectiva sobre o espaço e o tempo.

0 trabalho cenográfico de José Manuel Castanheira ascende já às 131 produções, algumas delas com projecção internacional (especialmente em França, Espanha e Brasil), representando um destacado contributo na definição de parte importante do teatro português das últimas décadas. A partir da experiência fundadora da Trafaria, José Manuel Castanheira tem vindo a desenvolver a sua obra, enriquecendo-a notavelmente. Trabalhou com os mais relevantes encenadores e grupos de teatro portugueses - Artistas Unidos, Novo Grupo / Teatro Aberto, Comuna / Teatro de Pesquisa, A Barraca, Teatro Hoje / Teatro da Graça, Teatro Experimental de Cascais, Companhia de Teatro de Almada. Estas colaborações concretizaram-se quer em espaços tradicionais (como os teatros Villaret, Trindade e D. Maria II), quer em locais inusuais (um velho palacete em ruínas, uma antiga fábrica de azulejos, como aconteceu no espectáculo 0 tio Vânia, em 1981, ou 0 avarento, em 1984).

Particularmente significativa, pela continuidade que a tem caracterizado, é a sua parceria com Rogério de Carvalho, iniciada em 1975 com a peça argentina Povoação vende-se, de Andrés Lizarraga, a qual atingiu os seus pontos mais altos com os grandes textos de Tchekov ( 0 tio Vânia, A gaivota, 0 jardim das cerejeiras, Platonov).
Fora do país, referência especial é devida ao contributo cenoplástico de Castanheira - quase sempre decisivo para a consecução do espectáculo - nas encenações de Ricardo Salvat da peça El incierto señor Don Hamlet, de Álvaro Cunqueiro (Centro Dramático da Galiza, 1991), de Eugénio Amaya da Elektra, de Jean Giraudoux (Teatro Romano de Mérida, 1997), de Juan Carlos Perez de la Fuente do texto San Juan, de Max Aub (Teatro Maria Guerrero, Madrid, 1998), de Sergi Belbel d'El alcalde de Zalamea, de Calderón de La Barca (Teatro Nacional da Catalunha, 2000), sem esquecer a Cármen pelo Ballet Nacional de Espanha em 1998 ou, no Brasil, A casa de boneca, de lbsen (encenação de Aderbal Freire-Filho, Teatro do Leblon do Rio de Janeiro, 2001), A prova, de David Auburn (no mesmo teatro e com o mesmo encenador, 2002), a ópera de Verdi Um baile de máscaras, no Teatro Municipal do Rio de Janeiro, ainda com encenação de Aderbal Freire (2004).

Mas seriam de citar todos os outros espectáculos para os quais, ao longo de trinta anos, José Manuel Castanheira soube criar e construir - com os mais diversos materiais e uma prodigiosa riqueza de invenção, através de um subtil jogo dialéctico entre o interior e o exterior, o que está por cima e o que está por baixo - o espaço 

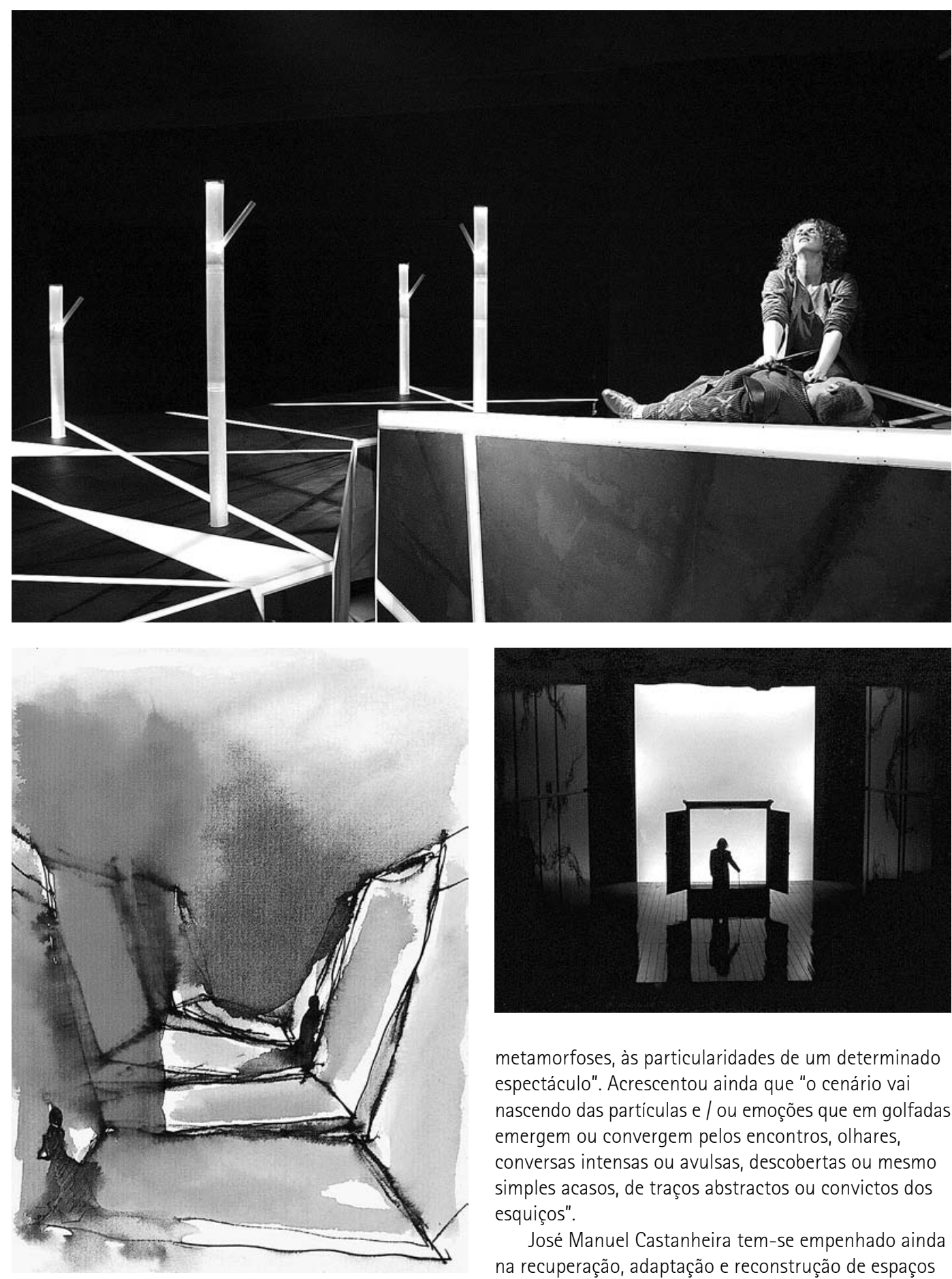

cénico adequado ao seu triplo relacionamento com o texto, o jogo dos actores e o público.

A seu respeito pôde falar-se, e com razão, da criação de uma "dramaturgia da cena": a inscrição das palavras e dos gestos das personagens num universo de formas, linhas, volumes, cores, luzes e sombras que é, ao fim e ao cabo, a metáfora do mundo.

Recentemente, José Manuel Castanheira retomou velhas inquietações a propósito da sua "experiência de fazer cenografia". No programa da ópera Os fugitivos com música de José Eduardo Rocha, libreto de Rui Zink e encenação de Paulo Matos (Teatro da Trindade, 2004) - o cenógrafo reflectiu acerca da "persistência de modelos espaciais que se adaptam, depois de múltiplas

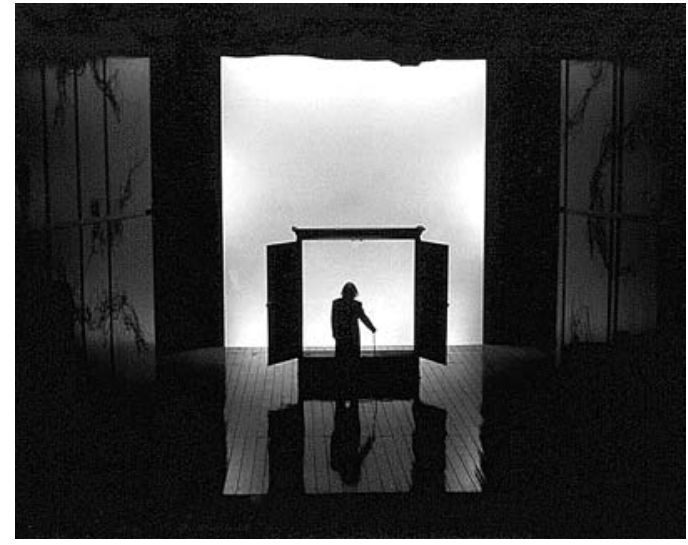

metamorfoses, às particularidades de um determinado espectáculo". Acrescentou ainda que "o cenário vai nascendo das partículas e / ou emoções que em golfadas emergem ou convergem pelos encontros, olhares, conversas intensas ou avulsas, descobertas ou mesmo simples acasos, de traços abstractos ou convictos dos esquiços".

José Manuel Castanheira tem-se empenhado ainda na recuperação, adaptação e reconstrução de espaços teatrais (Teatro Taborda em Lisboa, Teatros Aveirense e de S. Pedro do Sul), organizado e participado em colóquios e seminários sobre cenografia dentro e fora do pais, sendo também autor de um projecto de teatro flutuante, o

"Teatro do Rio, descendente dos sonhos e das águas de Belém", ainda por concretizar.

Um catálogo abrangente de toda a sua obra, e um caderno complementar, Une ruine en construction, foram publicados em 1993, por ocasião da exposição retrospectiva "Cenografias 1973-1993", com a colaboração de criadores, críticos e estudiosos nacionais e estrangeiros (entre os quais Yannis Kokkos, Ricard Salvat, José Triana, Guy-Claude François, Carlos Porto, João Brites), conhecimento e análise dessa obra. constituindo documentos fundamentais para o
La serrana de la Vera, de Luis Velez de Guevara, enc. Maria Ruiz, Centro Dramatico Nacional / Teatro Pavon Madrid, 2004, fot. José Manuel Castanheira.

El incierto señor Don Hamlet, de Álvaro Cunqueiro, enc. Ricardo Salvat, Centro Dramático Galego,1991, esquiço para o cenário. Ojardim das cerejas de Tchekov, enc. João Lourenço, Novo Grupo / Teatro Aberto, 1987, fot. José Manuel Castanheira. 